muscles. The pain became almost constant and she died, worn out, nine months from the commencement of her illness. Unfortunately, no post-mortem examination was permitted.

Erythromelalgia is an affection of the vaso-motor system, probably of the vaso-motor centres in the spinal cord-either an over-action of vaso-dilator or a paralysis of vaso-constrictor centres. Are there any means of localising the lesion more definitely? It has recently been shown by LaignelLavastine ${ }^{1}$ that by destroying the sympathetic cord in the whole length of the thorax of dogs and keeping the animals alive for some months there were produced spinal lesions, especially evident in the cells of the base of the anterior cornu and in the lateral cornu. This writer thinks it probable that the efferent fibres of the sympathetic have for the most part their origin in the cells of the lateral cornua. In the Revue de Médecine for October, 1903, there is what appears to be clinical confirmation of this research in the publication by Lannois and Porot of a case of erythromelalgia, the spinal cord in which actually presented lesions of these parts. A widow, aged 55 years, showed vaso-motor phenomena of the fingers of the left hand immediately after the death of her husband. Five weeks later she had a monoplegia of the left arm (shown by necropsy to be due to cortical softening). The extremities of the fingers were swollen like drumsticks and the nails were thin and grooved. A few weeks later the hand became cold and she had patches of gangrene on the toes. Post mortem the left crossed pyramidal and the right direct pyramidal tracts were degenerated. There was atrophy of the left half of the grey matter of the cord, affecting especially the anterior cornu in the cervical and dorsal regions. There was much diminution of the prominence that the lateral cornu gives ordinarily to the outer border of the grey matter. In the dorsal region there was almost complete disappearance of the lateral cornu and its cells, there being only two or three atrophied cells presenti.e., atrophy of the intermedio-lateral tract; there was also atrophy, indeed almost complete disappearance, of the column of small fusiform cells that normally exists at the base of the posterior cornu. Clarke's columns were intact. In the cervical region there was atrophy of the cells repre. senting the upward continuation of the intermedio-lateral tract-i.e., the antero-lateral group of cells of the anterior cornu. This atrophy of the intermedio-lateral tract was present throughout the upper dorsal cord and was out of all proportion more marked than the atrophy of the rest of the grey matter. The arteries of the cord were in a state of advanced degeneration. No lesions of peripheral nerves were found except some sheaths empty of myelin but containing intact axis cylinders, If these researches, experimental and clinical, are confirmed it will be possible to localise the vaso-motor lesions of erythromelalgia in the cells of the intermedio-lateral tract and in the small fusiform cells at the base of the posterior cornu. It is not necessary to point out the significance of the vascular degeneration in the cord in such cases.

Wells, Somerset.

\section{NOTE ON A CASE OF CHANCRE OF THE LIP AND ITS MODE OF INFEOTION.}

By Leopold G. HiLl, M.R.C.S. ENG., L.R.C.P. LOND., MEDICAI OFFICER, CHURCH MISSION HOSPITAL, PAKHOI, SOUTH CHINA.

DURING the past year a couple of well-marked cases of chancre of the lip have come under my notice in the mission hospital here, one of which has such a clear history of its origin that it is worth recording.

A male Chinese, aged 24 years, came to the mission hospital, on March 17th with an ulcer almost in the centre of his upper lip; it was very painful and partly covered with a blood scab. He had had it for about a fortnight, but the day before it was more painful, so he sought relief. The ulcer was of the size of a split pea and had the so-called parchment hard feeling about it. It was not causing much swelling around but the lip was held stiffly. There were two enlarged submaxillary glands visible, that on the left being of the size of a small nut and that on the right, the larger, that of a filbert. It was undoubtedly a chancre. It is unnecessary to go into the after-history except to say that under mercury by the mouth and inunction the chancre and enlarged glands disappeared and that the patient regained his usual health as soon as the debilitating effects of the drug passed off and also that 11 weeks after the onset of the disease he had some sus. picious symptoms of secondary syphilis-feverishness, pains in the bones, and slight sore throat-which soon cleared up and now he is in excellent health.

The point of interest is how he contracted the sore. His only child, some eight or nine months old, was being treated a month or so before and was then under treatment for congenital syphilis, consisting chiefly in a running at the nose, "snuffles," and emaciation-at that time beginning to improve and now a strong enough looking child. His wifehe married a widow-had had syphilis ten years ago, contracted, presumably, from her first husband; by him she had become pregnant twice and had had two miscarriages, carrying the foetus nearer to term each time, but not a living child by him. The first child by the second husband was born dead at full term; the second, a puny child at birth, is the one referred to as having the nasal discharge. The father is extremely proud and fond of this child and I had often seen him nursing it in its sickness, kissing it and fondling it with his mouth on the child's face in spite of the moisture coming from the nose. No doubt some of this infected a scratch or open sore on the delicate lip and produced the chancre.

Pakboi.

\section{SYMPTOMS OF SUFFOCATION IN AN INFANT \\ CAUSED BY A PIECE OF COAL LODGED \\ IN THE TRACHEA; OPERATION; RECOVERY. ${ }^{1}$ \\ By Walker DownIe, M.B., C.M., F.F.P.S. GLasG.} LECTURER ON DISEASES OF THE THROAT AND NOSE, GLASGOW UNIVERSITY AND WESTERN INFIRMARY.

ON Nov. 11th, 1903, an infant boy, aged 15 months, was left to play in the kitchen while his mother did some work in the washhouse. When his mother returned she found him sitting on the floor near to the fireplace. He was crying and gasping for breath, with the fingers of both hands in his mouth. The mother concluded that the child had put some of the cinders which were lying on the hearth in his mouth and that possibly he had swallowed some. During the rest of the day the child was very fretful, had considerable difficulty in breathing, would take no food, and frequently cried as if suffering pain. Throughout the night and the following day there was a steady increase in the difficulty of breathing. When the medical man was called he found the child suffering from what he considered to be laryngeal obstruction, and without delay had the child sent from the country to the Western Infirmary as an urgent case. The child was admitted late in the evening of Nov. 12th and was seen by me about 10 P.M. He was then pale and exhausted and while suffering from severe dyspnoea had no hoarseness-his cry was perfectly clear. The pulse was 148 per minute, the respirations were 64 per minute, and the temperature (which was taken with difficulty on account of his struggles for breath) was $100.4 \circ \mathrm{F}$. The marked indrawing of the intercostals and the epigastrium was an index to the serious nature of the obstructive difficulty present. By auscultation it was found that the amount of air entering the lungs was greatly deficient, that both sides were equally affected, and that the respiratory murmur, particularly towards the bases, was accompanied by mucous râles. The cause of the obstruction to the entrance of air was evidently in the trachea and probably was well down in that tube. An examination by the $x$ rays gave no sign of the lodgment of a foreign body.

For the removal of the foreign body, the presence of which was indicated by the history and the symptoms, inversion was first tried but without benefit. The child was then placed under chloroform. The larynx was inspected with the laryngoscope and found to be normal, af ter which tracheotomy was performed. When the tracheal cartilages were split and the edges of the incision held apart a black object, lying transversely and firmly fixed within the trachea, was seen at the level of the fourth ring. This

1 The case was shown and the notes were read at a meeting of the Glasgow Medico-Chirurgical Society on Nov. 20th, 1903 , 
was grasped with forceps and removed and it was found to be a piece of coal measuring half an inch long, by three sixteenths of an inch broad, and one-eighth of an inch thick. A tube was inserted lest any fragments might have been broken off and retained. As soon as the piece of coal was removed the child breathed with freedom, the chest expanded fully, and the child was asleep shortly after. Later, he again became restless and his temperature at 4 A.M. was $101.8^{\circ}$, his respirations were 58 , and his pulse was 144 per minute. At 8 A.M. on the 13 th his temperature was $100 \cdot 6^{\circ}$, his respirations were 46 , his pulse was 136 , and at $10 \mathrm{A.M}$. the tube was removed. From this time there was a gradual but steady improvement and on the 15th the evening temperature was $98.4^{\circ}$, the respiraticns were 28, and the pulse was 124 . The child is now well and the wound healed.

Glasgow.

\section{A aftirtor}

\section{HOSPITAL PRACTICE, BRITISH AND FOREIGN.}

Wulla autem est alia pro certo noscendi via, nisi quamplurimas e morborum et dissectionum historias, tum aliorum tum proprial collectas habere, et inter se comparare.-MoreagNI De Sed. et Caus. Morb., lib. iv., Procemium.

\section{ST. THOMAS'S HOSPITAL.}

SEVEN CASES OF INTESTINAL OBSTRUCTION.

(Under the care of Mr. G. H. Makins, C.B.)

THE following seven cases of intestinal obstruction seem worthy of brief record, since, besides possessing some surgical interest, no less than six of them, illustrating most of the more common causes of the condition, were met with during the course of a single major week at St. Thomas's Hospital. The first case which is added as affording an example of one other cause was admitted in the preceding major week.

CASE 1. Caoal vo'vulus. - The patient was a woman, 67 years of age. During the last 18 months she had been the subject of four or five distinct attacks of abdominal pain accompanied by vomiting sufficiently severe to confine her to bed. Ten days prior to her admission to hospital she was seized with severe pain in the lower abdomen, most acute in the region of the umbilicus. Obstruction of the bowels had been complete for six days, vomiting had been frequent, and neither flatus nor fæces had been passed per rectum. On admission the woman looked anxious and ill; vomiting of dark feculent smelling fluid was frequent. Constipation was absolute. Her tongue was furred but not very dry. Her pulse-rate was 108 and her temperature was $97^{\circ} \mathrm{F}$. Her abdomen was considerably distended; the prominence was median and on inspection gave the impression of a tumour rising from the pelvis. It was resonant throughout except in the right flank.

An operation having been decided upon, the abdomen was opened through the right rectus from just above the level of the umbilicus downwards. A hugely ballooned piece of bowel was at once disclosed occupying the whole field of operation. The incision was enlarged but the distended gut could not be delivered as it was tightly wedged into the pelvis. A trocar and cannula were therefore introduced and a large quantity of gas and liquid fæces was evacuated. The slackening of the tumour thus produced allowed of the hand being inserted into the pelvis beneath the sac and the piece of bowel was brought out. The intestine affected proved to be the cæcum and lower part of the ascending colon which was provided with an unusually long mesentery. The twist was through half a circle and involved the ascending colon about the centre of its length. The ileum remained viable. It was considered advisable completely to empty the loaded bowel which was then readily replaced, the two punctures having been securely sutured. The patient made an uneventrul recovery, the bowels acted spontaneously the day after the operation, and the stitch $\epsilon$ were removed from the abdominal wound on the eighth day. On the fourteenth day a localised collection of pus was evacuated from the lower part of the wound in the abdominal wall and at the end of a month the patient left the hospital recovered.

CASE 2. Carcinoma of the rectum.-The patient was a man, aged 43 years, with a history of chronic constipation which had existed for years and for the last two months was much aggravated and accompanied by abdominal pain. There was no history of passage of blood or mucus. On examination the abdomen was found to be highly distended, visible peristalsis being marked. On introduction of the finger into the rectum a growth was discovered extending within three inches of the anus and firmly fixed. Inguinal colotomy was performed and three weeks later the patient was transferred as " relieved" to Lambeth Infirmary.

CASE 3. Persistent Meckel's diverticulum.--The patient was a man, aged 41 years, who had not had any intestinal trouble until seven years ago, but since then had suffered from attacks of abdominal pain once or twice each year. These attacks were sometimes accompanied by vomiting but never by any marked constipation or diarrhcea. They were of sufficient severity to oblige him to discontinue his work as a clerk for a few days. Three days before admission a similar attack of pain occurred; it was of a gnawing character, never very severe, but was continuous and seemed to spread across the abdomen just below the level of the umbilicus. Vomiting persisted throughout and at the time of admission the bowels had not acted for four days. The abdomen was moderately distended; the tongue was moist; the pulse was 75 per minute, regular, and of fair strength ; and the tem. perature was $98^{\circ} \mathrm{F}$.

A three-inch incision was made through the right rectus, starting just above the level of the umbilicus. Collapsed gut was at once discovered in the pelvis and when followed up led to a band stretching from the ileum to the umbilicus. This was at once recognised as a broad Meckel's diverticulum. The distal end was freed from the umbilical attach. ment and the strangulation was relieved. The constricted part of the bowel was in good condition. The diverticulum was removed and the abdomen was closed. The patient made an uneventful recovery and left the hospital on the seventeenth day well. The diverticulum was a broad one with a lumen at the distal end at least one inch in diameter. It may be menti ned as a matter of interest that the solitary follicles in this part were enlarged and inflamed but no ulceration had taken place. In a former case published by Mr. Makins the diverticulum was riddled with perforations which he thought might be the result of previous follicular inflammation.

CASE 4. Intestinal adhesions. - The patient was a man, aged 21 years, who 12 years before admission had been stabbed in the left half of the epigastric region. Three weeks before admission he felt himself unwell, the motions were very offensive, at times he vomited, and on one occasion the matter was said to be feculent. During this period the bowels were irregular, constipation for as much as four days alternating with days on which the bowels were opened by enemata. On admission the bowels had not acted for some days; the tongue was dry and brown; the pulse was feeble and 84 per minute; and the temperature was $97^{\circ} \mathrm{F}$. The abdomen was not distended but marked peristalsis was observed around the umbilicus; the walls moved well. Nothing abnormal was discovered on palpation and there was resonance throughout. From the history and the general condition of the patient it was evident that the illness had commenced as a gastro-enteritis, followed by intestinal toxæmia. It seemed not the less clear that considerable obstruction existed in the course of the small intestine and an exploration was decided upon.

In spite of the cicatrix in the upper part of the left rectus over the cardiac end of the stomach it was thought better to make an incision through the right rectus, the centre of which corresponded with the level of the umbilicus, as it appeared unlikely that small intestine could be implicated at so high a level as the scar. This proved a considerable convenience, since the relation of the intestine to the scar which was after all found to exist was able to be investigated thoroughly and the danger of cutting directly down on adherent intestine was avoided. The jejunum was found attached to the scar and sharply kinked, dilated above the kink and considerably contracted below it. The adhesion was freed and the abdomen was closed. The after-progress of the patient was slow. For 12 days he lay with a sunken 'ace, dark rings around his eyes, and mentally much depressed. The bowels acted freely, on several days the condition amounting to severe diarrhœa; the pulse remained of poor 